\title{
Processing Effects on the Formability of Magnesium Alloy Sheets
}

\author{
Jan Bohlen ${ }^{1, *}$, Guadalupe Cano ${ }^{1}$, Daria Drozdenko ${ }^{2}$, Patrik Dobron ${ }^{2}{ }^{\mathbb{D}}$, Karl Ulrich Kainer ${ }^{1}$, \\ Sven Gall ${ }^{3}$, Sören Müller ${ }^{3}$ and Dietmar Letzig ${ }^{1}$ \\ 1 Magnesium Innovation Centre (MagIC), Helmholtz-Zentrum Geesthacht, Max-Planck Str. 1, \\ D 21502 Geesthacht, Germany; guadalupe.cano@hzg.de (G.C.); karl.kainer@hzg.de (K.U.K.); \\ dietmar.letzig@hzg.de (D.L.) \\ 2 Department of Physics of Materials, Charles University, Ke Karlovu 5, CZ 12116 Prague 2, Czech Republic; \\ drozdenko@karlov.mff.cuni.cz (D.D.); dobronp@karlov.mff.cuni.cz (P.D.) \\ 3 Extrusion Research \& Development Center, TU Berlin, Gustav-Meyer-Allee 25, D 13355 Berlin, Germany; \\ sven.gall@ingwerk.com (S.G.); soeren.mueller@tu-berlin.de (S.M.) \\ * Correspondence: jan.bohlen@hzg.de; Tel.: +49-4152-871995
}

Received: 31 January 2018; Accepted: 19 February 2018; Published: 23 February 2018

\begin{abstract}
As a generalized semi-finished product, the use of magnesium sheets requires addressing two major aspects of their processing: their microstructure and texture control, which are both essential for the forming behavior of such sheets during their forming to parts. Further, the processing of such sheets is complex, and therefore expensive, and requires simplification. In this work, magnesium alloys AZ31, ZE10, and ME21 are investigated in the form of conventionally rolled sheets, as well as in the form of extruded sheets. Their microstructural and textural development are correlated to their mechanical and forming properties. During extrusion, strong textures develop that hinder stretch-forming operations, even in rare earth-containing alloys. Chemical composition and process parameters have a significant impact on the texture development, and enable the design of sheet materials with weak textures and potentially enhanced formability.
\end{abstract}

Keywords: magnesium alloys; rolling; extrusion; sheet; forming limit curves; Electron backscatter diffraction (EBSD)

\section{Introduction}

Sheets are a fundamental form of semi-finished products, which are easily used in forming procedures for the production of near-net shaped parts [1,2]. Thus, the enhanced formability of magnesium alloy sheets is envisioned for forming operations for making use of the lightweight potential of magnesium and its alloys. In this regard, limits have been seen for a long time, which were based in the limited deformation behavior of magnesium alloys, and often associated with the hexagonal close-packed lattice structure of this metal and its alloys. Many works on the microstructure-property relationship [3-6] have concluded that the formation of strong textures, especially with a preferential alignment of basal planes in the sheet plane, is an important reason for limited formability. This limitation is primarily due to the limited strain accommodation, especially by basal slip [7], e.g., such textures are formed during the rolling process. However, rare earth-containing alloys have been found to enable significant texture changes during the rolling of magnesium sheets, resulting in a weaker alignment of basal planes in the sheet plane [7-10] or in textures with tilt components of basal planes. Especially, the latter type of texture has been correlated to higher strain accommodation and higher ductility and formability based on a potential balance of active deformation mechanisms [3,11].

Furthermore, a specific limitation for the manufacturing of magnesium sheets is the high technical effort that is needed during rolling. Due to a general low formability of the alloys, the degree of deformation 
that can be applied per rolling pass is low, even at the typically high processing temperatures. Intermediate annealing is required between rolling passes for material softening in complex rolling schedules with a high number of rolling passes. Actual works investigate alternative production methods for a more efficient manufacturing of magnesium sheets [12,13].

One possible way for the production of thin profiles with sheet character is the extrusion process. This well-established method also allows the production of magnesium profiles with complex shapes, even if extrusion ratios are high. Technically, the potential to tailor sheet thickness by comprehensive die design appears to be limited due to the potentially limited width of such profiles. Earlier works have referred to this aspect, and shown that the production of magnesium sheets is feasible based on extrusion for a number of magnesium alloys [14-16]. Therefore, an improvement in efficiency results from extrusion being applied as a one-step method to the final product shape.

This opens up the possibility of relating different sheets from conventional rolling procedures to those from extrusion, in order to reveal the impact of different forming processes on the microstructural development and the related mechanical and forming properties. Conventional rolling is a multi-step process that is often carried out as cold deformation, i.e., in temperature ranges where dynamic recrystallization does not determine the microstructural development, followed by annealing, i.e., static recrystallization [12]. On the contrary, extrusion is a process with a strong impact of dynamic recrystallization at high degrees of deformation. This fundamental difference allows assuming changes in the microstructural development. In this work, rolled sheets from a classical rolling procedure are compared with sheets from a one-step extrusion process. Results from microstructural characterizations are linked to mechanical properties and formability tests. For this purpose, a comparison between different magnesium alloys with and without the content of rare earth elements with different microstructural development tendencies are investigated.

\section{Materials and Methods}

Three magnesium alloys-AZ31, ZE10, and ME21—are used in form as a rolled sheet and extruded sheet. The alloy composition and general properties are shown in Table 1. As rolled sheets, the material of former Salzgitter Magnesium Technology $\mathrm{GmbH}$ was used in an O-temper condition, which is a hot-rolled, leveled, and annealed condition. No information on the rolling procedures is available in this case. The final thickness of the sheets was $1.5 \mathrm{~mm}$. The developed microstructure and texture as well as the mechanical properties of these sheets are comparable to other works in the literature $[3,7,10,17]$.

Table 1. Properties and chemical composition of sheets and band; values in wt $\%, \mathrm{Mg}$ balance.

\begin{tabular}{ccccccccc}
\hline Alloy & Thick-Ness [mm] & Al & Zn & Mn & Ce & La & Nd & Zr \\
\hline AZ31 (rolled sheet) & 1.5 & 3.11 & 0.88 & 0.38 & - & - & - & - \\
ZE10 (rolled sheet) & 1.5 & - & 1.27 & - & 0.08 & 0.06 & 0.02 & 0.09 \\
ME21 (rolled sheet) & 1.5 & 1.73 & - & - & 0.53 & - & - & - \\
AZ31 (extruded sheet) & 0.8 & 2.7 & 0.74 & 0.32 & - & & & \\
ZE10 (extruded sheet) & 0.8 & - & 1.22 & - & 0.17 & 0.14 & 0.04 & - \\
ME21 (extruded sheet) & 0.8 & - & - & 1.73 & 0.77 & - & - & - \\
ZN10 (extruded band) & 2.0 & - & 0.98 & - & - & - & 0.57 & - \\
\hline
\end{tabular}

The extruded sheets were produced from the cast billets of the respective alloys. The alloy composition is also included in Table 1. Extrusion was carried out on an 8.3-MN horizontal extrusion press at the Extrusion R\&D Center at the Technical University Berlin. In this process, an open tube profile is directly extruded and opened during the process, followed by flattening. Details on the exact process can be found in earlier work by Gall et al. [14]. The extrusion ratio was 51:1, and the ram speed $1 \mathrm{~mm} / \mathrm{s}$. An important aspect is that a width of up to $170 \%$ of the diameter of the container was obtained for the sheet. Extrusion temperatures varied for the three alloys: $380{ }^{\circ} \mathrm{C}$ for AZ31, $450{ }^{\circ} \mathrm{C}$ for 
ZE10, and $420^{\circ} \mathrm{C}$ for ME21. A final leveling for $60 \mathrm{~min}$ at $380^{\circ} \mathrm{C}$ followed by air-cooling was carried out for receiving sheets with a thickness of $0.8 \mathrm{~mm}$.

For the discussion of the results of this study, additional direct extrusion experiments to a flat band with a $20 \mathrm{~mm} \times 2 \mathrm{~mm}$ cross-section were carried out using a 2.5-MN automatic extrusion press of Müller Engineering (Müller Engineering GmbH \& Co. KG, Todtenweis/Sand, Germany) at the Helmholtz-Zentrum Geesthacht. The extrusion ratio remains similar with 1:49. A Mg-Zn-Nd alloy (extruded band of ZN10, see Table 1) has been extruded at varied extrusion speeds and temperatures, in order to reveal the impact of the processing parameters on the microstructural and textural development. Annealing of the cast billet was applied for $16 \mathrm{~h}$ at $500{ }^{\circ} \mathrm{C}$.

Microstructural analysis was carried out through applying standard metallography procedures, including an etchant based on picric acid to reveal grains, grain, and twin boundaries [18]. Texture measurements were carried out on polished samples ground to the midplane of the sheets, and six pole figures were measured up to a tilt angle of $70^{\circ}$ and used for the recalculation of the orientation distribution function and full pole figures. $\mathrm{Cu} K \alpha$ radiation was used, and a beam size of $3 \mathrm{~mm} \times 1 \mathrm{~mm}$ ensured the detection of at least $10^{6}$ grains per measurement. An open-source code MTEX [19] has been applied to receive complete pole figures. A 50-kN testing machine, Zwick Z050 (Zwick GmbH \& Co KG, Ulm, Germany), was used to carry out quasi-static tensile tests at room temperature with a constant initial strain rate of $10^{-3} \mathrm{~s}^{-1}$ in two directions, rolling direction (RD) or extrusion direction (ED), respectively, as well as the transverse direction (TD).

Formability tests were carried out at an exemplary temperature of $200{ }^{\circ} \mathrm{C}$ for rolled ME21 and the three extruded sheets. The results for the rolled AZ31 and ZE10 sheets were not repeated in this work, but rather taken from an earlier work [3]. Specimen geometries according to Hasek [20] were used to represent different strain paths. Such samples were scaled down to $50 \%$ of the original size to round blanks with a diameter of $100 \mathrm{~mm}$ in order to meet the width restrictions of the extruded sheets. Sample geometries were realized by semi-circular recesses on round blanks with diameters up to $40 \mathrm{~mm}$. A hemispherical punch with a diameter of $50 \mathrm{~mm}$ has been used for the deformation of clamped samples. The clamping force was $200 \mathrm{kN}$, and the punch speed was $60 \mathrm{~mm} / \mathrm{min}$. A lubricant based on polytetrafluorethylene foil with a thickness of $500 \mu \mathrm{m}$ and oiled with OKS 352 has been applied. Local strain measurements during the tests were carried out with an optical deformation measuring system, ARAMISTM (GOM, Braunschweig, Germany). The sample surfaces were sprayed with a statistical pattern based on graphite spray. Two high-resolution cameras took pictures of the surface at a sampling rate of $12 \mathrm{~Hz}$. A system-related software allowed the recalculation of local true strains during the test, and especially before the fracture of the samples. The results were used to determine the forming limits for each sample geometry and its related strain paths. Thus, the respective major strains and minor strains were identified, and the forming limit curve (FLC) was revealed.

Electron backscatter diffraction (EBSD) was carried out for orientation imaging on samples in order to reveal the properties of the different fractions of grains. A field emission gun scanning electron microscope Zeiss Ultra 55 (Carl Zeiss AG, Oberkochen, Germany), EDAX/TSL EBSD system and Hikari detector (AMETEK Inc., Berwyn, PA, USA) was employed at an accelerating voltage of $15 \mathrm{kV}$ using samples that underwent metallography procedures and electropolishing. A software "TSL Orientation Imaging Microscopy Analysis" of EDAX@ (AMETEK Inc., Berwyn, PA, USA) was used to analyze the measurements. This especially includes the application of a function allowing the separation of grains with varied grain orientation spread (GOS). While GOS characterizes the variation of grain orientations from their average orientation, grains with limited GOS can be separated. In this study, an arbitrary limit of $1^{\circ}$ is used as a separator, following the approach that grains with low orientation spread can be understood as recrystallized grains [21], whereas others are not. 


\section{Results}

\subsection{Characterization of Rolled and Extruded Magnesium Sheets}

Figure 1 shows the micrographs from longitudinal sections of the rolled sheets as well as pole figures to present the texture. AZ31 exhibits a bimodal microstructure with fractions of larger and smaller grains, respectively. ZE10 also reveals a recrystallized microstructure. However, an elongation of the grains that are parallel to the RD is still visible. ME21 shows a more homogeneous microstructure, with larger grains compared to the other two alloys. Average grain sizes are very similar, with $11 \mu \mathrm{m}$ for AZ31, $10 \mu \mathrm{m}$ for ZE10, and $14 \mu \mathrm{m}$ for ME21. Significant differences in the textures are consistent with earlier findings for such sheets $[3,7,9,10]$. The typical feature of the AZ31 sheet is a strong alignment of basal planes in the sheet plane, with a broader angular tilt to RD than to TD. Prismatic planes are randomly distributed parallel to the normal direction (ND) of the sheet. The same is found in the ME21 sheet, which is still expressed more weakly, whereas the basal pole figure exhibits split peaks with a tilt towards the RD. ZE10 shows a very weak texture, with weak split peaks towards the transverse direction and a component with prismatic planes perpendicular to the rolling direction.
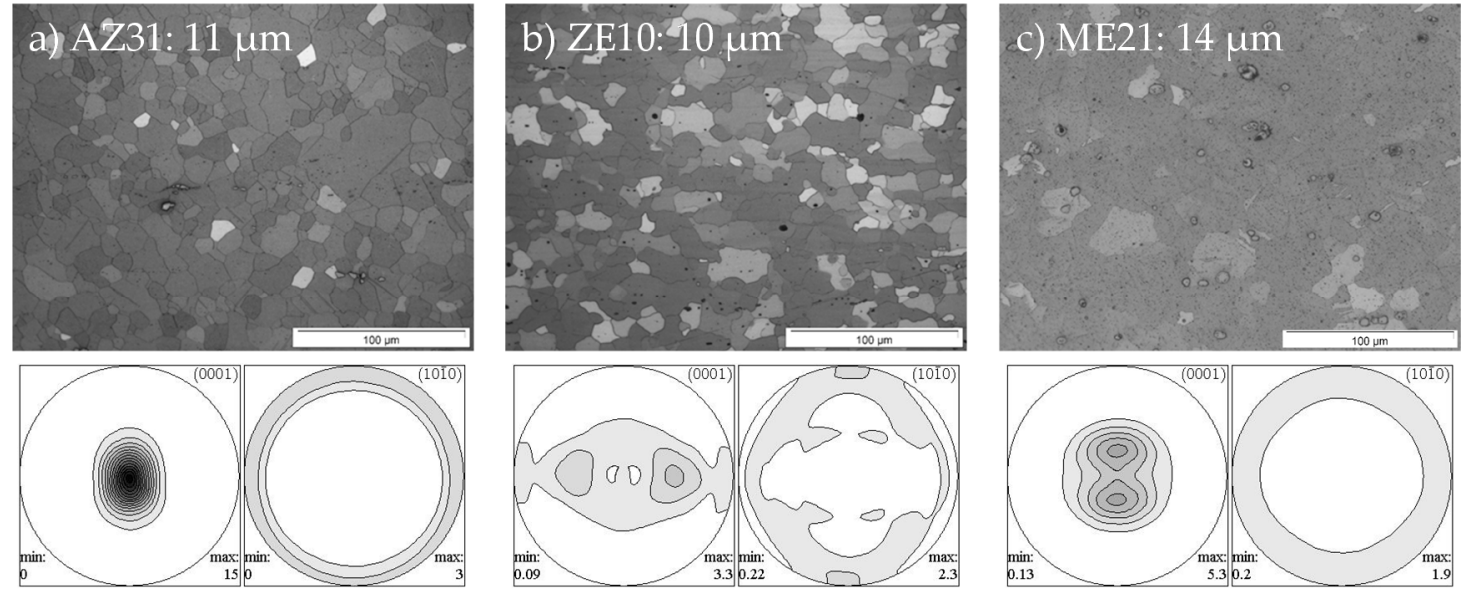

Figure 1. Micrographs with average grain sizes from longitudinal sections and pole figures of rolled sheets in annealed condition: (a) AZ31; (b) ZE10; (c) ME21 (micrographs: rolling direction (RD) horizontal, normal direction (ND) vertical; pole figures: RD vertical, transverse direction (TD) horizontal, lines in 1.0 multiples of random distribution steps).

Figure 2 shows the same results for the extruded sheets. Likewise, a bimodal microstructure is observed for AZ31, with an average grain size of $16 \mu \mathrm{m}$. The ZE10 sheet appears to have a fully recrystallized microstructure, and a larger average grain size of $24 \mu \mathrm{m}$. In the case of the ME21 sheet, a significantly finer grained microstructure is revealed, with an average grain size of $9 \mu \mathrm{m}$. In all three cases, the horizontal extrusion direction is easily seen due to elongated grains or stringer particles parallel to this direction. The textures are different compared to the rolled counterparts in Figure 1. In the case of AZ31, an extremely strong alignment of basal planes parallel to the sheet plane is found together with a small TD component, and a six-peak prismatic symmetry concurrent to the basal alignment. Also, ZE10 exhibits a strong basal alignment, with a broader angular distribution towards ED than towards the TD, which is fundamentally different from the rolled sheet. In the case of ME21, a strong texture with two split peaks towards the ED is also observed. 

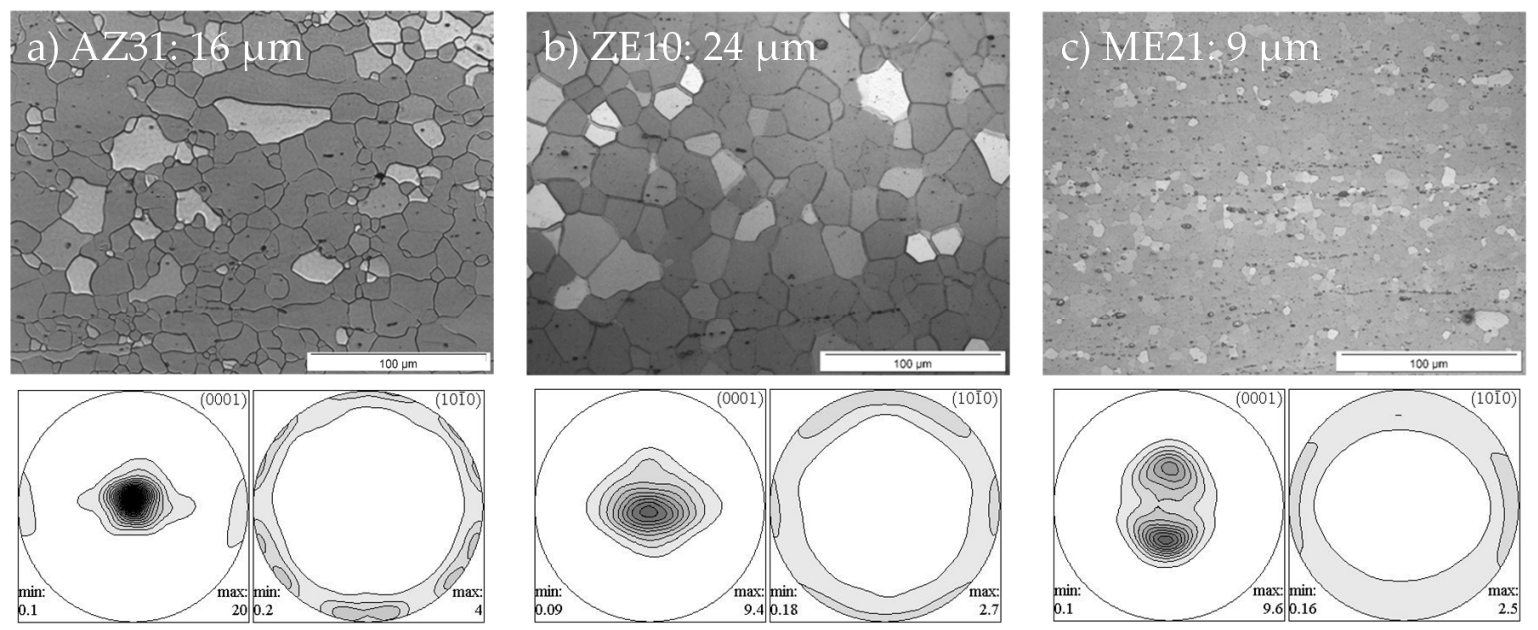

Figure 2. Same as Figure 1 for extruded and annealed sheets: (a) AZ31; (b) ZE10; (c) ME21 (micrographs: RD horizontal, ND vertical; pole figures: RD vertical, TD horizontal, lines in 1.0 multiples of random distribution steps).

\subsection{Mechanical and Forming Properties of the Sheets}

The mechanical properties of the sheets are collected in Table 2. Example stress-strain diagrams of the corresponding tensile tests are displayed in Figures 3 and 4. The strong texture of the rolled AZ31 sheet corresponds to high yield stresses and ultimate stresses, respectively. The uniform strains and fracture strains are slightly lower for the extruded sheet than for the rolled sheet. The stress levels in the TD are higher compared to the RD, which is a typical finding that has been associated with the angular tilt of basal planes being broader towards the RD than the TD $[7,22]$. For the extruded sheet, this relationship is not initially clear. However, it can be assumed that more grains with tilt out of the ND towards the RD are found in Figure 2a. Grain size effects on the mechanical properties are not assumed. For ZE10, distinct differences between the rolled and extruded sheet are found with respect to the anisotropic behavior. Rolled ZE10 reveals a significantly higher yield stress in the RD than in the TD, whereas for extruded ZE10, the opposite is observed. The direction with lower stress levels also corresponds to higher uniform strain and fracture strain. The weak texture of the rolled ZE10 sheet favors basal slip, especially along the TD, and therefore allows higher strain levels to be achieved compared to the RD. The alignment of basal planes in the extruded ZE10 sheet is not clearly broader in one direction. However, at lower intensity levels, higher angular spreads are revealed for the ED, which is consistent with the enhanced activity of basal slip and corresponding lower stress levels, but higher strain levels. For ME21, there is a distinct difference in the anisotropic behavior when comparing the rolled sheet and the extruded sheet. In case of the rolled sheet, rather low differences are found in any property between the RD and the TD. With the same texture consideration as above, the TD tests revealed higher stress properties than the RD tests. In case of the extruded sheet, this difference is much more pronounced, which is also at the expense of both uniform and fracture strain in the TD test. This difference between the two sheets is associated with a distinctly stronger texture of comparable type after extrusion, as well as with a clearly finer-grained microstructure. In this case, it becomes obvious that the stronger texture may be beneficial for the direction with enhanced basal slip, but not for other directions. 
Table 2. Mechanical properties from tensile tests in the RD or the extrusion direction (ED), and the $\mathrm{TD}$, at room temperature, of the rolled and extruded sheets (standard deviations: stresses cca. $2 \mathrm{MPa}$; strains cca. $0.3 \%$ ); TYS: tensile yield stress, UTS: ultimate tensile stress.

\begin{tabular}{cccccc}
\hline Alloy & Orientation & TYS & UTS & Uniform Strain & Fracture Strain \\
\hline \multirow{2}{*}{ AZ31 (rolled) } & RD & 155 & 264 & 15.6 & 24.2 \\
& TD & 197 & 267 & 13.2 & 24.7 \\
\hline \multirow{2}{*}{ ZE10 (rolled) } & RD & 160 & 235 & 11.3 & 25.3 \\
& TD & 105 & 218 & 18.9 & 29.7 \\
\hline \multirow{2}{*}{ ME21 (rolled) } & RD & 117 & 208 & 9.4 & 20.2 \\
& TD & 137 & 227 & 10.3 & 21.0 \\
\hline \multirow{2}{*}{ AZ31 (extruded) } & ED & 163 & 261 & 13.9 & 18.7 \\
& TD & 188 & 262 & 11.0 & 21.5 \\
\multirow{2}{*}{ ZE10 (extruded) } & ED & 92 & 218 & 17.2 & 11.0 \\
\hline \multirow{2}{*}{ ME21 (extruded) } & TD & 143 & 246 & 8.7 & 20.8 \\
& ED & 131 & 244 & 14.4 & 10.6 \\
\hline
\end{tabular}
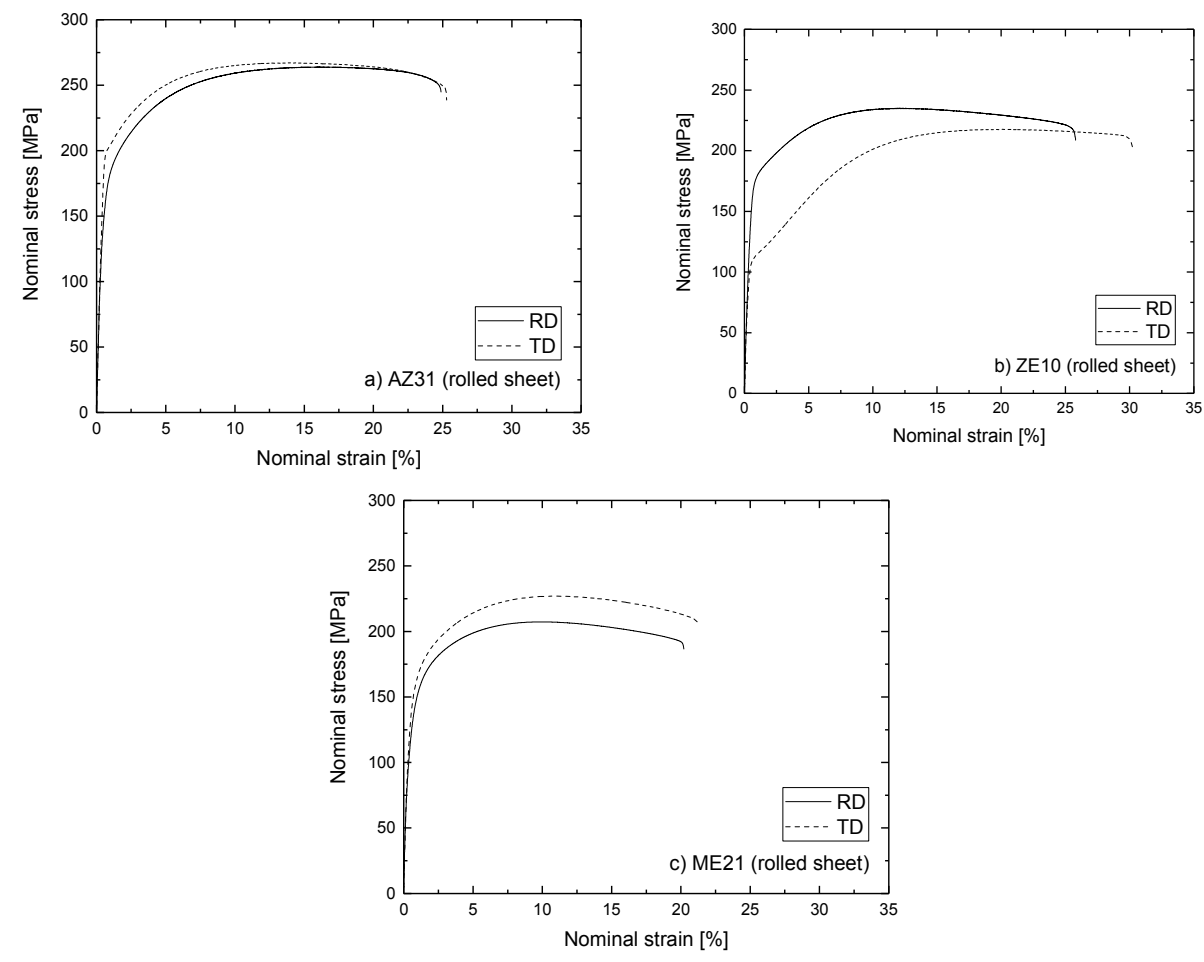

Figure 3. Stress-strain diagrams in the RD and the TD for the rolled magnesium sheets; (a) AZ31; (b) ZE10; (c) ME21.

In Figure 5, the forming limit curves (FLC) as result of Nakajima tests at $200{ }^{\circ} \mathrm{C}$ of the rolled sheet and the extruded sheets are shown. As formability at room temperature remains low [3], a comparison is drawn for an exemplary temperature in a range of potential application of forming procedures. It is worthwhile to repeat that the forming operation, along with the left-hand side of the FLC, corresponds to strain conditions that allow material contraction along the minor strain axis (width contraction), but low or no thickness reduction. Vice versa, on the right-hand side of the FLC stretch, the forming operations require positive strain in all of the sheet plane directions, and the material flow is realized by thinning the sheet. A typical minimum is associated with a plane strain condition in the V-shaped curves. Such results are visible for the rolled sheets in Figure 5a. Generally, strains are lowest for ME21, 
and slightly higher for AZ31. The highest strain levels are observed for ZE10. In comparison to the above-mentioned forming operations, for ME21 and AZ31, strains on the left-hand side of the FLC are higher compared to those on the right-hand side. Only in case of ZE10 does this appear to be balanced. In comparison, the results for the FLCs of the extruded sheets in Figure $5 b$ appear different. Only low strains are achieved in the three alloys on the right-hand side of the FLC, where positive minor strains are required. With an increasing possibility of material flow along the minor strain direction on the left-hand side of the FLC, comparable strains-as in Figure 5a for the rolled sheets—can be realized, especially for ZE10 and ME21. Similar to the case of the rolled sheet, ZE10 reveals the highest strain in such strain paths compared to the other two alloy sheets. AZ31 and ZE10 do not differ much in this result.
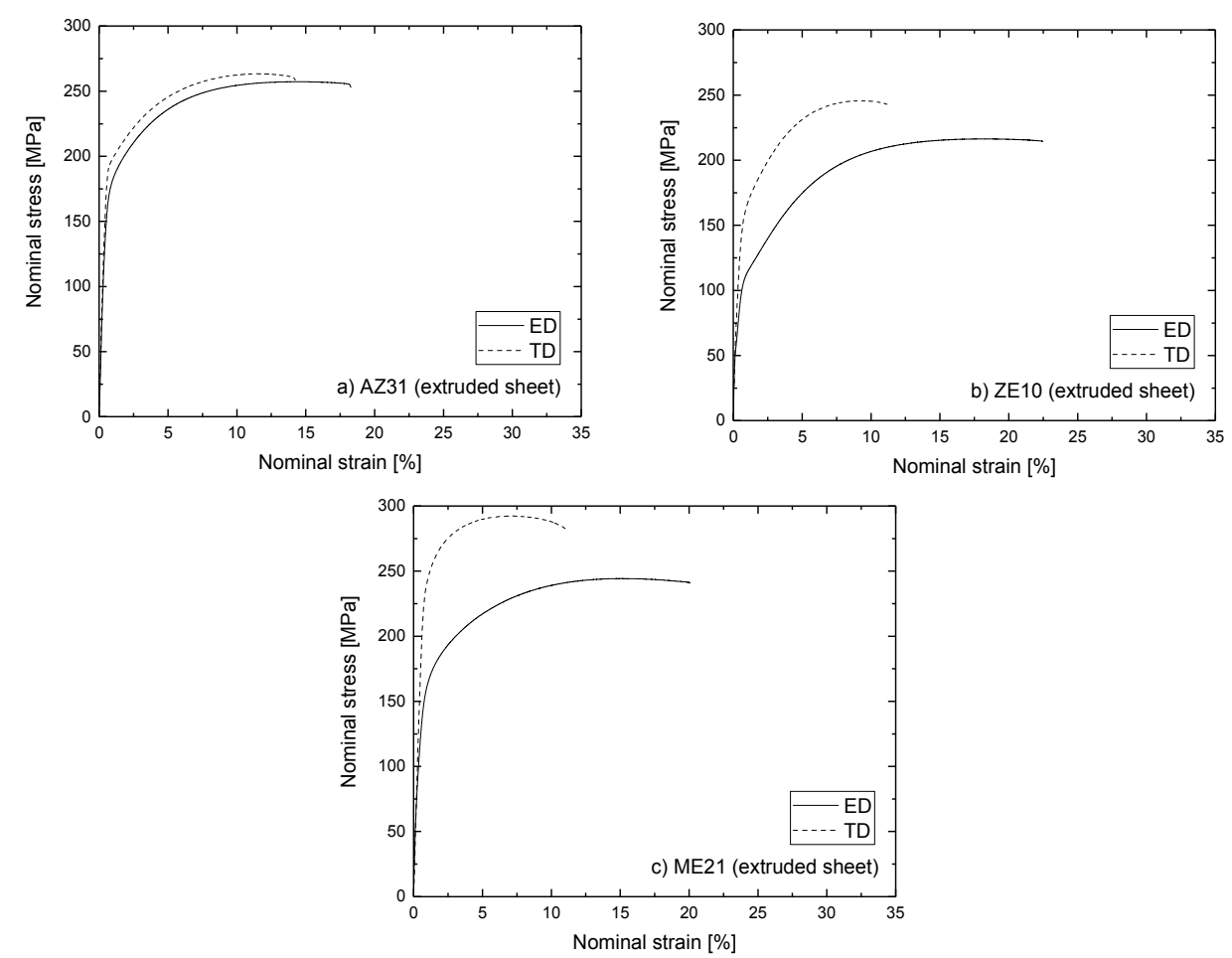

Figure 4. Stress-strain diagrams in the RD and the TD for the extruded magnesium sheets; (a) AZ31; (b) ZE10; (c) ME21.
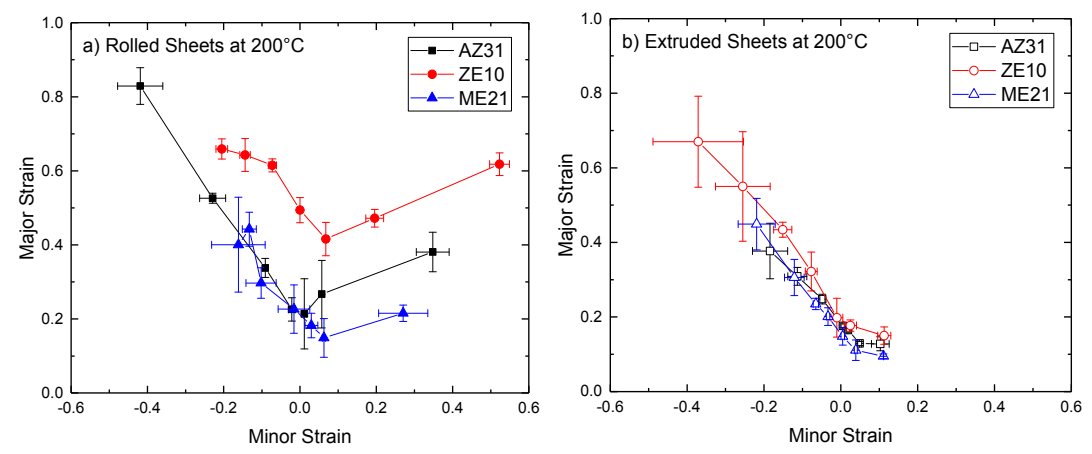

Figure 5. Forming limit diagrams for the (a) rolled and (b) extruded sheets at a temperature of $200{ }^{\circ} \mathrm{C}$ (results for AZ31 and ZE10 in (a) are repeated from Stutz et al. [3]). 


\subsection{Microstructure Development during Forming}

The microstructural and textural development during forming has been observed in a series of EBSD measurements, which was exemplary for the extruded sheet samples after forming. Samples with geometry I and VII refer to the series of Hasek samples, and represent the one with the highest recession radius resulting in the lowest minor strain and the one without recession resulting in the highest minor strain, i.e., the extrema of the FLCs. The applied software allows restricting the selection of grains in the measured area to those with limited grain orientation spread (GOS). Grains with low GOS, i.e., lower than $1^{\circ}$ in this study, are associated with newly recrystallized grains due to their low internal orientation spread, whereas grains with high GOS, e.g., higher than $3^{\circ}$ in this study, are related to a fraction of the microstructure that underwent deformation without new grain formation due to recrystallization [23]. This selection enables a separate analysis of the different fraction of grains, and the ability to relate their microstructural features as well as their texture to the full microstructure and to the original sheet before deformation.

Results for the extruded AZ31 sheet are collected in Figure 6a. After forming tests with a sample geometry I grains appear with an elongation parallel to the ED. The fraction of recrystallized grains $\left(\mathrm{GOS}<1^{\circ}\right)$ is small, and such grains form bands or necklace-like rings around those in an unrecrystallized condition (GOS $>3^{\circ}$ ). Boundaries revealed from the EBSD measurements are mainly associated with grain boundaries, and are only associated with a few extension twins. The texture of the fraction of deformed grains forms a basal alignment parallel to the sheet plane, as well as a TD spread. This is associated with a six-peak symmetry of the prismatic planes, which is often associated with prismatic slip [24] along similar strain paths. The latter feature is also developed after deformation with geometry VII; however, the TD spread does not appear. Thus, a strengthening of the basal alignment of the grains is observed, which is more distinct for the unrecystallized fraction of the grains, but weaker for the recrystallized fraction of tje grains.

a) AZ31 after forming at $200^{\circ} \mathrm{C}$

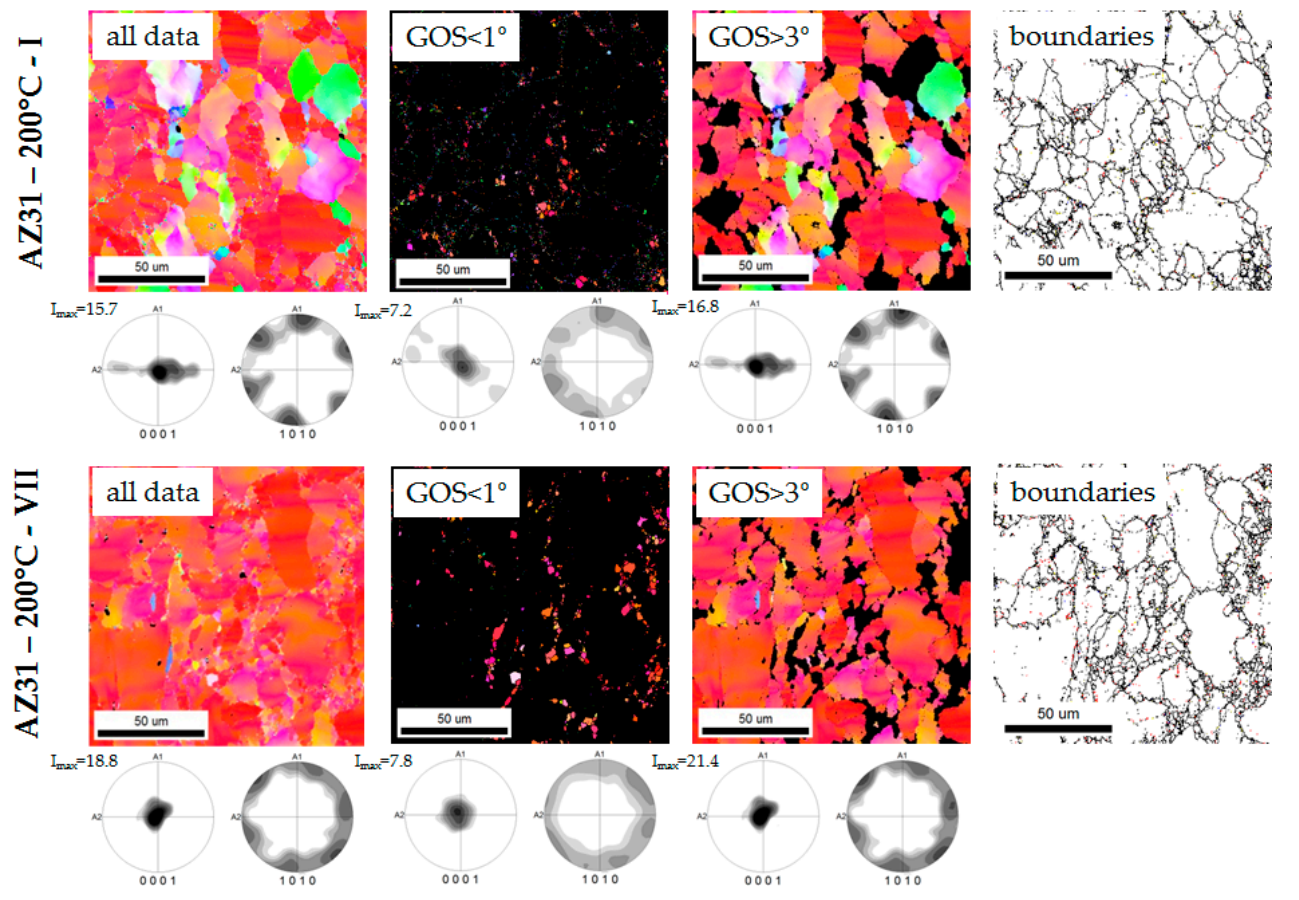

Figure 6. Cont. 
b) ZE10 after forming at $200^{\circ} \mathrm{C}$
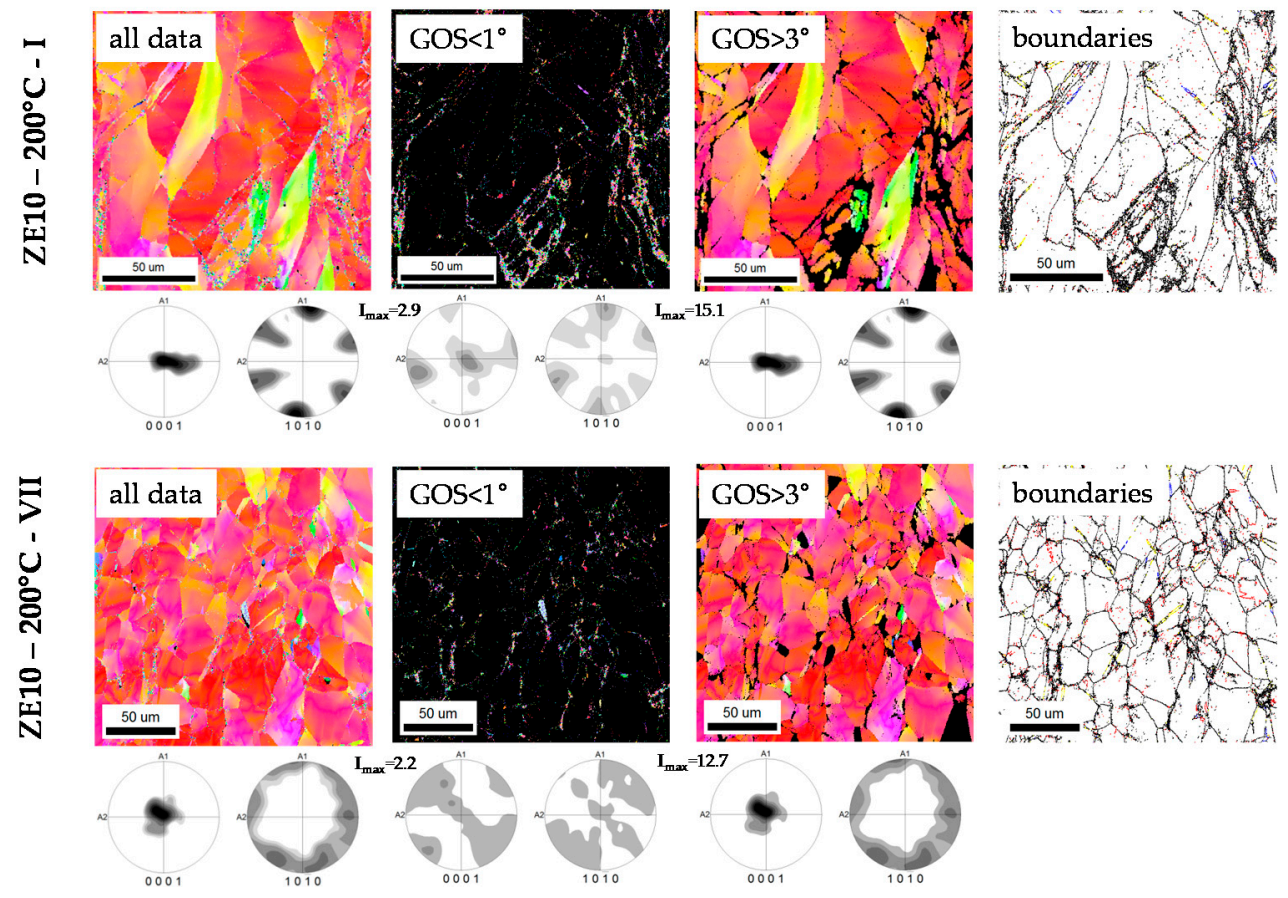

c) ME21 after forming at $200^{\circ} \mathrm{C}$
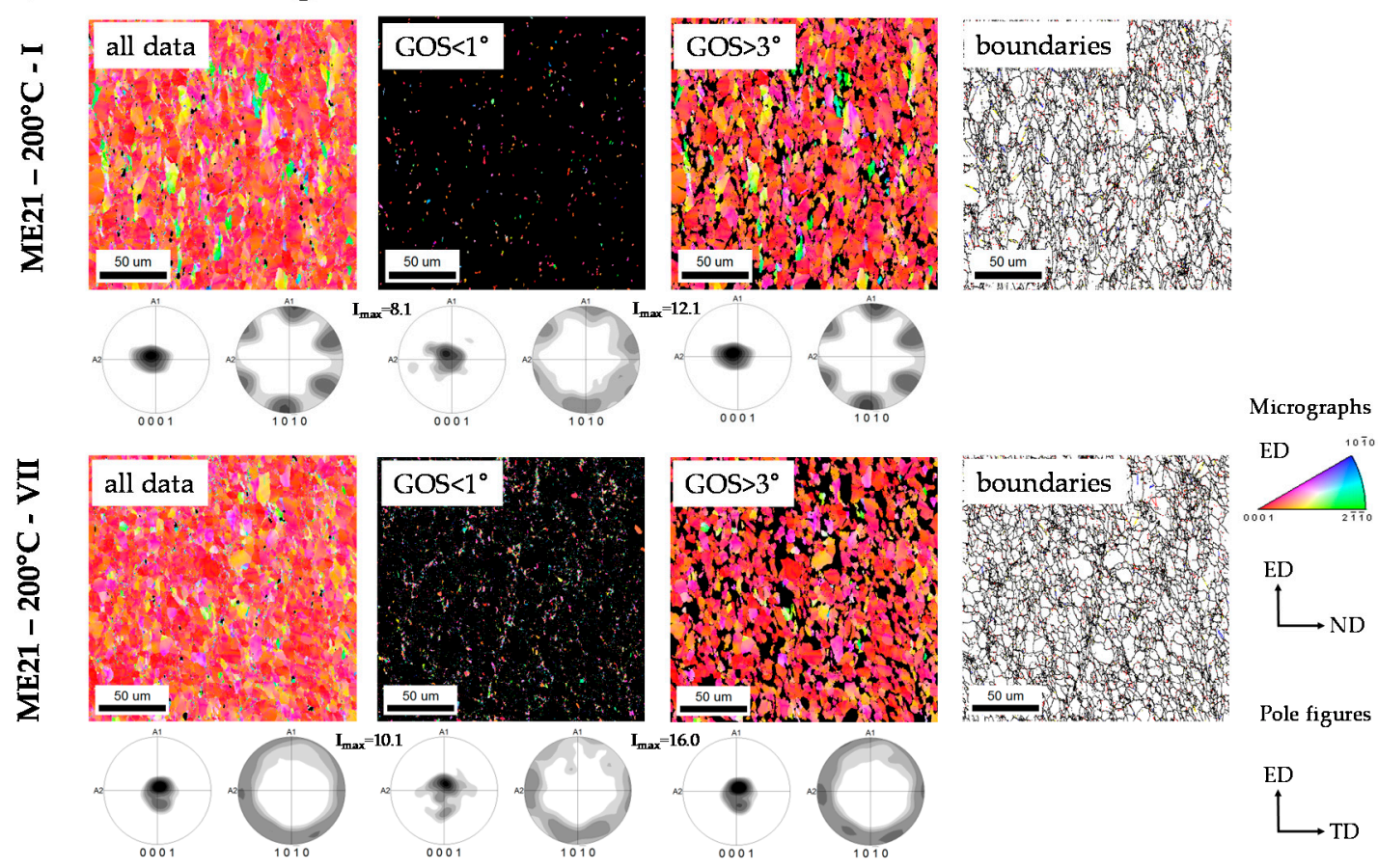

Boundaries:

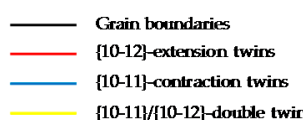

Figure 6. Electron backscatter diffraction (EBSD) orientation maps and pole figures of two selected sample geometries, I and VII, after the forming test of (a) AZ31, (b) ZE10, and (c) ME21; orientation map oriented parallel to ED. 
In Figure 6b, similar results are shown for the extruded ZE10 sheet. Deformation along both samples, geometries I and VII, show a strengthening of the original texture. Only the recrystallized fraction of grains is associated with a very weak texture and no distinct basal alignment, as is typically observed in recrystallized ZE10 sheets (see Figure 1b). Interestingly, this fraction of grains is arranged in band-like structures as the sole alloy of this study, which corresponds to many different types of twins. The weak texture development during the recrystallization of rolled rare earth-containing magnesium sheets has been associated with such twins previously [8,25]. Results for the extruded ME21 sheet in Figure $6 c$ are similar to those of AZ31 in Figure 6a, despite the different starting texture of the sheet and the smaller grain size. However, no specific arrangement of recrystallized grains can be observed for this alloy, and no twin boundaries are found after deformation.

\section{Discussion}

\subsection{The Microstructural and Textural Development during Extrusion}

Significant differences of the sheet properties are based on the different microstructural and textural development during sheet processing. Many works have discussed mechanisms that influence the development of weaker textures during the rolling of sheets. This specifically includes changes in the activities of deformation mechanisms, i.e., slip modes and their effect on orientation changes [7,24,26-28], as well as different types on twins and shear bands [8,25,29]. Furthermore, the impact of dynamic and static recrystallization during rolling and annealing has been analyzed $[9,30,31]$. Although the investigation of such different mechanisms is beyond the scope of this work, and mostly hidden in the microstructure after the final annealing procedures, the main differences between the rolled sheet alloys are obvious. AZ31 as a classical magnesium alloy forms strong textures in bimodal microstructures, whereas ME21 forms weaker textures that are associated with the content of rare earth in the alloy. Furthermore, ZE10 with rare earth and $\mathrm{Zn}$ as alloying elements are known to lead to weak textures with a tilt of basal planes towards the TD.

During extrusion, a single high step of deformation is applied that is accompanied with a distinct directionality due to the shape of the profile, which itself is accompanied by dynamic recrystallization. However, during rolling, low degrees of deformation per pass are combined with intermediate annealing, i.e., static recrystallization, which in combination may lead to a less significant development of the texture. Thus, the extruded sheets tend to form stronger textures in all of the alloys, with a preference of an alignment of basal planes in the sheet plane, specifically in AZ31 and ZE10. In the case of the extruded AZ31 sheet, the development of a strong version of the rolled sheet texture may be understood as a classical expected texture development. ME21 exhibits a texture with a tilt of basal planes towards the ED and no prismatic fiber at all. This texture component has been observed in rare earth-containing magnesium extrusions [32], which are also often described for round bars with rotational symmetry [21,25]. A concentration of orientations in the sheet plane will thus result in strong split peaks towards the ED, as observed in ME21. In the case of the extruded ZE10, a rather coarse-grained microstructure correlates to a distinct texture with the alignment of basal planes in the sheet plane, i.e., more a "classical" texture development during processing that is not consistent with the potential growth limitation effect of such a component in rare earth-containing alloys. Stanford et al. [25] have described an effect in extruded round bars where at higher extrusion temperatures, the growth limitation effect may be overcome, and a distinct alignment of basal planes parallel to the extrusion direction remains. Note that in the case of the forming procedures, the deformation of extruded ZE10 corresponds to the development of deformation bands with different types of twins, as has been observed in rare earth-containing alloys during rolling as well [8]. This fraction of the microstructure reveals a very weak, almost random texture. Although such mechanisms are active in this alloy, they do not control the texture development during the manufacturing of the sheet, hypothetically because of processing effects and the resulting distinct grain growth achieved. 
For a reference for such findings, exemplary extrusion experiments of flat bands were conducted with varied processing parameters in order to confirm different microstructural and textural developments. In the case of Figure 7, an example alloy, ZN10, is investigated and extruded into a flat band. Three variations of the alloy include change in the extrusion rate and the extrusion temperature. While the example uses shapes with similar extrusion ratios during the extrusion of sheets, the processability at the given temperatures and speeds may be limited for a larger extrusion. Thus, the usage of a potentially successful texture design may be limited in practical cases. However, Figure 7 reveals the impact of an increased extrusion rate in terms of grain coarsening, together with a distinct alignment of basal planes. Meanwhile, at a lower speed, a texture with two split components is revealed, resulting in weak split peaks of basal planes towards the ED and the TD. The latter is lost, and split peaks towards RD remain distinct at the higher extrusion rate. This effect corresponds to visibly enhanced grain growth. An additional increase of the extrusion temperature is then associated with a tendency to align basal planes in the sheet plane, but with a broad tilt of basal planes towards the TD. The similarity of this texture with the one for the extruded ZE10 sheet in Figure $2 b$ may be noted, as well as the similarity of the two peaks split in Figure $7 \mathrm{~b}$, which corresponds to the texture of the ME21 extruded sheet. Adjustment of the processing for the respective alloys guides towards a potential broader distribution with a weaker alignment of basal planes, as shown in Figure 7a. An additional alloy study on similar alloys in earlier work by Bohlen et al. [33] shows that ME21 can be formed into bands (sheets) with a texture similar to that in Figure $7 \mathrm{a}$ at low extrusion temperatures.
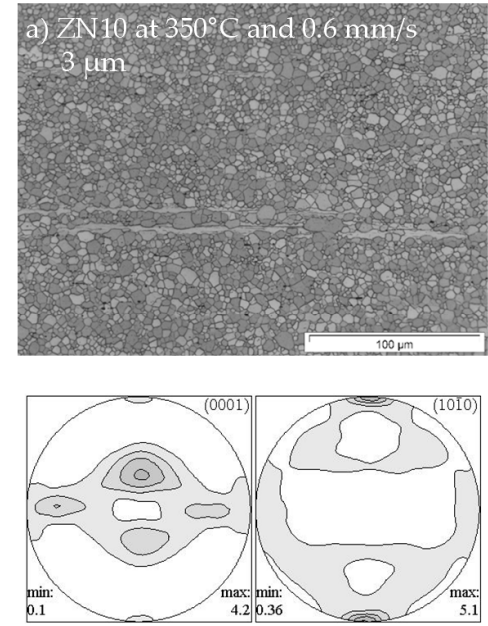
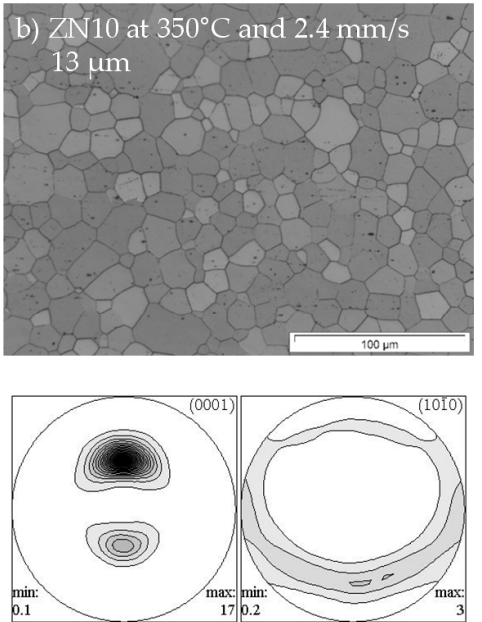
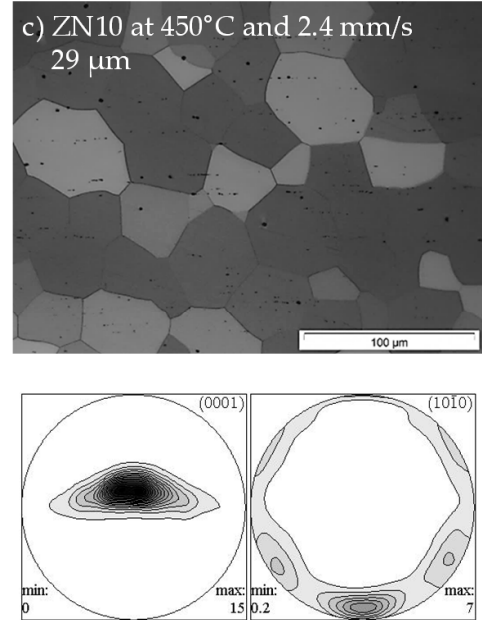

Figure 7. Microstructure and texture of extruded flat bands of alloy ZN10 with varied extrusion temperatures and extrusion rates (ram speed): (a) $350{ }^{\circ} \mathrm{C}$ and $0.6 \mathrm{~mm} / \mathrm{s}$ (average grain size: $3 \mu \mathrm{m}$ ); (b) $350{ }^{\circ} \mathrm{C}$ and $2.4 \mathrm{~mm} / \mathrm{s}$ (average grain size: $13 \mu \mathrm{m}$ ); (c) $450{ }^{\circ} \mathrm{C}$ and $2.4 \mathrm{~mm} / \mathrm{s}$ (average grain size: $29 \mu \mathrm{m})$, legends as in Figures 1 and 2.

\subsection{Development of Mechanical and Forming Properties}

Table 3 collects the main findings of the microstructural analysis as well as the mechanical and forming behavior of the sheets in order to guide the following discussion.

The mechanical properties of the sheets appeared to be correlated to the microstructure and texture of the sheets. The direction that corresponds to a broader angular spread of basal planes exhibited a lower yield stress, and this effect was more significant if the textures were weaker, especially if fewer basal planes were orientated parallel to the sheet plane. The latter orientation is especially unfavorable for any deformation test. Then, the preferential activation of basal slip is supposed to determine the mechanical behavior [7,22]. Furthermore, grain size effects apply: the smaller the average grain size, the higher the stress levels achieved, especially for the yield stresses. Note that rather low uniform strains were found perpendicular to the distinctly favorable alignments for the activation of basal slip. 
A weaker but distinct texture with two basal split peaks towards the RD (or the ED) reduced the stress levels of the sheets, despite an additional influence of the coarser grain structure. For example, for the extruded ME21, which had a stronger version of the same texture as the rolled ME21 sheet, stress anisotropy became distinct, whereas the uniform strain was higher in the RD at comparable fracture strain, but lower strain levels were revealed for the TD. It was visible that such a texture strengthening is also not favorable for the stretch formability on the right-hand side of the FLC.

With respect to the forming behavior, many differences in the microstructure and the texture of these sheets are accompanied by a significant difference in the thickness of the sheets, which was $1.5 \mathrm{~mm}$ in the case of the rolled sheets, and only $0.8 \mathrm{~mm}$ in the case of the extruded sheets. For Al-sheets, a general thickness effect on the formability has been reported [34]. For AZ31 sheets, some works referred to a limitation of formability if the sheet thickness is lower [35,36]. Furthermore, in geometries where the material flow was limited to the thickness reduction (positive minor strain), a limitation was also stronger if textures were strong, and basal planes were aligned parallel to the sheet plane or in any way unfavorable for a contribution of basal slip to strain accommodation along the ND. As all three extruded sheets exhibited a tendency to develop such strong textures, the formability along such strain paths remained limited. An increased angular spread of basal planes, i.e., weaker texture but not textures with distinct split peaks, resulted in a potentially easier activation of deformation mechanisms, and in a distinct increase of the biaxial formability, such as in case of the rolled ZE10. For this alloy sheet, a balance between the limiting strains along different strain paths was observed.

Especially in the case of the extruded sheets, Figure 6 confirmed that dynamic recrystallization does not occur significantly during forming, as the fractions of recrystallized microstructure remained very low for all three alloys. It has been shown in earlier work [3] that dynamic recrystallization can occur during the formation of the AZ31 sheet at elevated temperatures, which corresponds especially to increased strain levels achieved on the right-hand side of the FLC. Thus, increasing the temperature will especially increase strain levels on the right-hand side of the FLC [16]. Therefore, material softening due to recrystallization is an important mechanism for enhanced stretch formability. The same work [3] also showed that higher degrees of recrystallization can lead to enhanced material softening, and therefore lower strains, especially on the left-hand side of the FLC. Thus, the impact of material softening due to dynamic recrystallization needs to be balanced for a generalized improved formability.

Table 3. Overview of the main findings from a microstructural analysis, mechanical analysis, and examination of the formation behavior of the six sheets of this study.

\begin{tabular}{cccccc}
\hline Alloy & Processing & $\begin{array}{c}\text { Thick-Ness } \\
{[\mathbf{m m}]}\end{array}$ & $\begin{array}{c}\text { Texture (Basal Plane } \\
\text { Characterization) }\end{array}$ & Mechanical Properties & Formability \\
\hline AZ31 & rolled & 1.5 & $\begin{array}{c}\text { Distinct alignment in } \\
\text { sheet plane }\end{array}$ & $\begin{array}{c}\text { Low mechanical } \\
\text { anisotropy }\end{array}$ & $\begin{array}{c}\text { Low stretch formability, } \\
\text { higher uniaxial formability }\end{array}$ \\
\hline ZE10 & rolled & 1.5 & $\begin{array}{c}\text { Weak texture } \\
\text { with TD tilt }\end{array}$ & $\begin{array}{c}\text { Strong anisotropic } \\
\text { behavior, high ductility }\end{array}$ & $\begin{array}{c}\text { High formability along all } \\
\text { strain paths }\end{array}$ \\
\hline AZ31 & rolled & 1.5 & Weak split peaks to RD & $\begin{array}{c}\text { Low mechanical } \\
\text { anisotropy }\end{array}$ & $\begin{array}{c}\text { Low stretch formability, low } \\
\text { uniaxial formability }\end{array}$ \\
\hline ZE10 & extruded & 0.8 & $\begin{array}{c}\text { Strong alignment in } \\
\text { sheet plane }\end{array}$ & $\begin{array}{c}\text { Low mechanical } \\
\text { anisotropy }\end{array}$ & $\begin{array}{c}\text { No stretch formability, lower } \\
\text { uniaxial formability compared } \\
\text { to a rolled sheet }\end{array}$ \\
\hline ME21 & extruded & 0.8 & $\begin{array}{c}\text { Weaker alignment in } \\
\text { sheet plane }\end{array}$ & $\begin{array}{c}\text { Strong anisotropic } \\
\text { behavior }\end{array}$ & $\begin{array}{c}\text { No stretch formability, highest } \\
\text { uniaxial formability of } \\
\text { extrusions }\end{array}$ \\
\hline
\end{tabular}

\section{Conclusions}

Flat product extrusion enables the manufacturing of magnesium sheets with low sheet thickness in a one-step process. The results are sheets with fully recrystallized microstructures and strong 
textures. The alignment of basal planes remains especially distinct, even in rare earth-containing alloys, unlike classically rolled counterparts.

This texture development is the result of the massive deformation applied in a one-step extrusion process, but can be changed by adjusting the extrusion parameters. Partly recrystallized fine-grained microstructures at low extrusion temperatures and speeds reveal two weak split peak components, whereas enhanced grain size development results in a strong split peak component with a tilt to the ED. If temperature and speed are high enough to enhance grain growth, texture developments that are specific to rare earth elements can be overcome, and an alignment of basal planes parallel to the sheet plane results.

Textures that exhibit a tilt of basal planes can be associated with lower stress properties and enhanced strain properties parallel to the tilt direction. A comparison of rolled and extruded sheets in forming procedures reveals reduced forming limits, especially in stretch-forming operations if textures are strong and the sheets are very thin, whereas forming operations with negative minor strains can be significantly higher. In this regard, even textures with strong split peaks are not favorable. Enhanced formability is associated with weak textures, but is not associated with distinct texture components for enhanced strain accommodation by basal slip and the onset of dynamic recrystallization during the forming procedure.

Acknowledgments: The authors would like to thank Günter Meister for his help with the casting of magnesium billets, Alexander Reichart for his help with sample preparation. The work on the extrusion of magnesium sheets and their investigation received funding from the Deutsche Forschungsgemeinschaft (Grant BO 2461/3-1; MU 2963/6-2). Work on the investigation of processing effects has been enabled by funding of the Czech Science Foundation (Grant No. 17-21855S). Guadalupe Cano is grateful for funding which allows his research stay at the Helmholtz-Zentrum Geesthacht by the National Council of Science and Technology of Mexico (CONACyT) and the German Academic Exchange Service (DAAD).

Author Contributions: The presented work combines achievements from different projects with linked contributions of the authors. Sven Gall, Jan Bohlen and Sören Müller analyzed the mechanical and forming behavior of the extruded sheets in this study. Jan Bohlen, Dietmar Letzig and Karl Ulrich Kainer contribute with the overview of the behavior of rolled sheets. Guadalupe Cano, Daria Drozdenko, and Patrik Dobron revealed results on the alloy and process design for the microstructure and texture development of rolled sheets and extruded flat products. The authorship shared the effort of creating the written manuscript of this paper.

Conflicts of Interest: The authors declare no conflict of interest.

\section{References}

1. Hirsch, J.; Al-Samman, T. Superior light metals by texture engineering: Optimized aluminum and magnesium alloys for automotive applications. Acta Mater. 2013, 61, 818-843. [CrossRef]

2. Friedrich, H.; Schumann, S. Research for a "new age of magnesium" in the automotive industry. J. Mater. Process. Technol. 2001, 117, 276-281. [CrossRef]

3. Stutz, L.; Bohlen, J.; Kurz, G.; Letzig, D.; Kainer, K.U. Influence of the processing of magnesium alloys az31 and ze10 on the sheet formability at elevated temperature. Key Eng. Mater. 2011, 473, 335-342. [CrossRef]

4. Dreyer, C.E.; Chiu, W.V.; Wagoner, R.H.; Agnew, S.R. Formability of a more randomly textured magnesium alloy sheet: Application of an improved warm sheet formability test. J. Mater. Process. Technol. 2010, 210, 37-47. [CrossRef]

5. Lee, J.-Y.; Yun, Y.-S.; Suh, B.-C.; Kim, N.-J.; Kim, W.-T.; Kim, D.-H. Comparison of static recrystallization behavior in hot rolled Mg-3Al-1Zn and Mg-3Zn-0.5Ca sheets. J. Alloys Compd. 2014, 589, 240-246. [CrossRef]

6. Suh, J.; Victoria-Hernandez, J.; Letzig, D.; Golle, R.; Yi, S.; Bohlen, J.; Volk, W. Improvement in cold formability of az31 magnesium alloy sheets processed by equal channel angular pressing. J. Mater. Process. Technol. 2015, 217, 286-293. [CrossRef]

7. Bohlen, J.; Nürnberg, M.R.; Senn, J.W.; Letzig, D.; Agnew, S.R. The texture and anisotropy of magnesiumzinc-rare earth alloy sheets. Acta Mater. 2007, 55, 2101-2112. [CrossRef]

8. Hantzsche, K.; Bohlen, J.; Wendt, J.; Kainer, K.U.; Yi, S.B.; Letzig, D. Effect of rare earth additions on microstructure and texture development of magnesium alloy sheets. Scr. Mater. 2010, 63, 725-730. [CrossRef] 
9. Al-Samman, T.; Li, X. Sheet texture modification in magnesium-based alloys by selective rare earth alloying. Mater. Sci. Eng. A 2011, 528, 3809-3822. [CrossRef]

10. Basu, I.; Al-Samman, T.; Gottstein, G. Shear band-related recrystallization and grain growth in two rolled magnesium-rare earth alloys. Mater. Sci. Eng. A 2013, 579, 50-56. [CrossRef]

11. Yi, S.; Bohlen, J.; Heinemann, F.; Letzig, D. Mechanical anisotropy and deep drawing behaviour of AZ31 and ZE10 magnesium alloy sheets. Acta Mater. 2010, 58, 592-605. [CrossRef]

12. Bohlen, J.; Kurz, G.; Yi, S.; Letzig, D. 10-Rolling of magnesium alloys. In Advances in Wrought Magnesium Alloys; Woodhead Publishing: Cambridge, UK, 2012; pp. 346-375.

13. Essadiqi, E.; Jung, I.H.; Wells, M.A. 7-Twin roll casting of magnesium. In Advances in Wrought Magnesium Alloys; Woodhead Publishing: Cambridge, UK, 2012; pp. 272-303.

14. Gall, S.; Müller, S.; Reimers, W. Extrusion of magnesium sheets with increased width. In Proceedings of the 10th International Conference on Technology of Plasticity (ICTP), Steel Research International, Special Edition, Aachen, Germany, 25-29 September 2011; pp. 286-290.

15. Gall, S.; Coelho, R.S.; Müller, S.; Reimers, W. Mechanical properties and forming behavior of extruded AZ31 and ME21 magnesium alloy sheets. Mater. Sci. Eng. A 2013, 579, 180-187. [CrossRef]

16. Bohlen, J.; Schlung, O.; Gall, S.; Müller, S.; Letzig, D. Formability of extruded magnesium alloy sheets with different textures. In Magnesium Technology 2016; Singh, A., Solanki, K., Manuel, M.V., Neelameggham, N.R., Eds.; Springer International Publishing: Cham, Switzerland, 2016; pp. 251-256.

17. Bohlen, J.; Hantzsche, K.; Kainer, K.U.; Wendt, J.; Fuskova, L.; Boelhauve, P.; Letzig, D. Rolling of ternary Mg-Zn alloys containing rare earth elements. In Proceedings of the Mg 2012, 9th International Conference on Magnesium Alloys and Their Applications, Vancouver, BC, Canada, 8-12 July 2012.

18. Kree, V.; Bohlen, J.; Letzig, D.; Kainer, K.U. The metallographical examination of magnesium alloys. Prakt. Metallogr. Pract. Metallogr. 2004, 41, 233-246.

19. Bachmann, F.; Hielscher, R.; Schaeben, H. Texture analysis with mtex-Free and open source software toolbox. Solid State Phenom. 2010, 160, 63-68. [CrossRef]

20. Hasek, V. Untersuchung und theoretische beschreibung wichtiger einflußgrößen auf das grenzformänderungsschaubild. Blech Rohre Profile 1978, 25, 213-220, 285-292, 493-499, 613-627.

21. Bohlen, J.; Yi, S.; Letzig, D.; Kainer, K.U. Effect of rare earth elements on the microstructure and texture development in magnesium-manganese alloys during extrusion. Mater. Sci. Eng. A 2010, 527, 7092-7098. [CrossRef]

22. Agnew, S.; Liu, K.; Kenik, E.; Vishwanathan, S. Magnesium Technology; Kaplan, H., Ed.; TMS: Warrendale, PA, USA, 2002; pp. 169-174.

23. Bohlen, J.; Wendt, J.; Nienaber, M.; Kainer, K.U.; Stutz, L.; Letzig, D. Calcium and zirconium as texture modifiers during rolling and annealing of magnesium-zinc alloys. Mater. Charact. 2015, 101, 144-152. [CrossRef]

24. Styczynski, A.; Hartig, C.; Bohlen, J.; Letzig, D. Cold rolling textures in AZ31 wrought magnesium alloy. Scr. Mater. 2004, 50, 943-947. [CrossRef]

25. Stanford, N.; Barnett, M.R. The origin of "Rare earth" Texture development in extruded mg-based alloys and its effect on tensile ductility. Mater. Sci. Eng. A 2008, 496, 399-408. [CrossRef]

26. Agnew, S.R.; Yoo, M.H.; Tome, C.N. Application of texture simulation to understanding mechanical behavior of $\mathrm{Mg}$ and solid solution alloys containing Li or Y. Acta Mater. 2001, 49, 4277-4289. [CrossRef]

27. Hadorn, J.P.; Hantzsche, K.; Yi, S.; Bohlen, J.; Letzig, D.; Wollmershauser, J.A.; Agnew, S.R. Role of solute in the texture modification during hot deformation of mg-rare earth alloys. Metall. Mater. Trans. A 2012, 43A, 1347-1362. [CrossRef]

28. Sandlöbes, S.; Zaefferer, S.; Schestakow, I.; Yi, S.; Gonzalez-Martinez, R. On the role of non-basal deformation mechanisms for the ductility of mg and Mg-Y alloys. Acta Mater. 2011, 59, 429-439. [CrossRef]

29. Mackenzie, L.W.F.; Pekguleryuz, M.O. The recrystallization and texture of magnesium-zinc-cerium alloys. Scr. Mater. 2008, 59, 665-668. [CrossRef]

30. Ion, S.E.; Humphreys, F.J.; White, S.H. Dynamic recrystallisation and the development of microstructure during the high temperature deformation of magnesium. Acta Metall. 1982, 30, 1909-1919. [CrossRef]

31. Stanford, N. The effect of rare earth elements on the behaviour of magnesium-based alloys: Part 2Recrystallisation and texture development. Mater. Sci. Eng. A 2013, 565, 469-475. [CrossRef] 
32. Brokmeier, H.-G. Hot rectangular extrusion textures of six Mg-alloys via neutron diffraction. Adv. Eng. Mater. 2017. [CrossRef]

33. Bohlen, J.; Cano, G.; Kurz, G.; Kainer, K.U.; Letzig, D.; Drozdenko, D.; Chmelík, F.; Dobroň, P. Profile shape effect on the texture and mechanical properties of extruded rare earth containing magnesium alloys. Acta Phys. Pol. A 2018, accepted.

34. Dilmec, M.; Halkaci, H.S.; Ozturk, F.; Livatyali, H.; Yigit, O. Effects of sheet thickness and anisotropy on forming limit curves of aa2024-t4. Int. J. Adv. Manuf. Technol. 2013, 67, 2689-2700. [CrossRef]

35. Ricci, P.; El Mehtedi, M.; Barone, L.; Spigarelli, S. Effects of temperature and sheet thickness on formability of AZ31 magnesium alloy. Mater. Sci. Forum 2009, 604-605, 147-152. [CrossRef]

36. Forcellese, A.; Gabrielli, F.; Simoncini, M.; Mehtedi, M.E. Thickness effect on the formability of AZ31 magnesium alloy sheets. Key Eng. Mater. 2011, 473, 313-318. [CrossRef]

2018 by the authors. Licensee MDPI, Basel, Switzerland. This article is an open access article distributed under the terms and conditions of the Creative Commons Attribution (CC BY) license (http://creativecommons.org/licenses/by/4.0/). 